Printed in Great Britain

\title{
The Virulence of Biochemical Variants of Streptococcus pyogenes
}

\author{
BY NUALA CROWLEY \\ From the Department of Microbiology of the Royal Free Hospital School of \\ Medicine, Royal Free Hospital, Gray's Inn Road, London W.C. 1
}

(Received 24 July 1964)

\begin{abstract}
SUMMARY
Two biochemical variants were obtained from a strain of Streptococcus pyogenes, type 19. One variant, known as 'starch-positive', always produced amylomaltase, readily forming starch from maltose. The other variant, known as 'starch-negative', did not usually form starch from maltose in the same cultural conditions. The starch-positive variant had low mouse virulence and the starch-negative variant had high mouse virulence. The starch positive variant was avirulent for the rat, but the starch-negative variant had some rat virulence. Both variants had plenty of $\mathbf{M}$ antigen in precipitin tests and showed good anti-phagocytic power both in bactericidal tests with human blood and in surface phagocytosis tests with isolated human leukocytes. The mouse virulence of the starchpositive variant was enhanced by casein polypeptide and by human plasma. Starch-positive and starch-negative variants obtained from a type 12 strain also had the same properties.
\end{abstract}

\section{IN'TRODUCTION}

Strains of group A streptococci grown in the presence of maltose or its higher homologues produce an amylose (Crowley \& Jevons, 1955; Crowley, 1959; Baum $\&$ Crowley, 1960). In thus utilizing maltose, these variant streptococci resemble the mutant strain of Escherichia coli discovered by Monod \& Torriani (1950) which formed an amylose from maltose through the enzyme amylomaltase. Crowley (1959) found that starch-forming streptococci were present in cultures of certain strains of many different group A serotypes though varying greatly in numbers from strain to strain. Large numbers were found in cultures of strains associated with acute glomerulonephritis and acute rheumatic fever. Because of this possible relationship, of which there is no direct proof, the properties of these amylomaltaseproducing streptococci were of some interest. The present work was undertaken to determine whether group A streptococci with the biochemical marker of amylomaltase production were either more or less pathogenic than other streptococcal cells, or possessed of any other unique property which might be related to particular aspects of streptococcal infection in man. This paper describes some properties of starch-positive and starch-negative variants derived from a mixed parent strain, with special reference to the production of the type-specific $M$ antigen, mouse virulence and anti-phagocytic properties. 


\section{METHODS \\ Streptococcal strains and cultures}

The group A strain used for the most part was IRP 118, type 19, received in 1957 from Dr R. C. Lancefield, The Rockefeller Institute. Two other strains used were OP,PS, type 12 and type 6 'glossy', both received in 1957 from the Streptococcus Reference Laboratory, Public Health Laboratory Service. All the strains were preserved by freeze-drying but for day-to-day work cultures were deep-frozen at $-10^{\circ}$ in brain heart infusion broth (Difco), which was the nutrient broth used throughout. The nutrient agar base used in culture plates was prepared with Hartley digest broth supplied by the Park Hospital, Lewisham, unless otherwise stated in the text.

Amylomaltase production, expressed as starch in colonies on maltose-containing medium, was detected by exposing culture plates to iodine vapour, which generally killed the streptococci. The culture plates were, however, always replicated by velveteen imprint (Lederberg \& Lederberg, 1952), and colonies chosen for propagation were picked off from another culture plate which had not been exposed to iodine.

Quantitative assay of starch production. Two methods were used, the first being the modification of that of Pucher, Leavenworth \& Vickery (1948) described by Crowley (1959) in which streptococcal suspensions were incubated for $5 \mathrm{hr}$ at $37^{\circ}$ with $1.6 \%$ maltose. The culture deposits were then resuspended in $10 \mathrm{ml}$. phosphate buffer ( $\mathrm{pH} \mathrm{7.0)}$ and extinctions were measured at $650 \mathrm{~m} \mu$ in a Unicam spectrophotometer. The starch was then extracted from the streptococcal cells by perchloric acid and precipitated from this extract by iodine. The starch was then hydrolysed, the glucose estimated and the final result expressed as the \% starch/amount of growth, making use of the theoretical factor of 0.90 to convert glucose into starch. The second method also depended on an extraction with perchloric acid, and utilized $18 \mathrm{hr}$ cultures in $20 \mathrm{ml}$. broth containing $1 \%(\mathrm{v} / \mathrm{v})$ maltose. The centrifuged culture deposit was first washed with phosphate buffer $(\mathrm{pH} \mathrm{7 \cdot 0})$ and then suspended in $4 \mathrm{ml}$. perchloric acid (Analar $72 \% 1$ vol. + distilled water 1 vol.) and stood at bench temperature for $1 \mathrm{hr}$. The suspension was then centrifuged, and the supernatant containing the starch neutralized with $20 \% \mathrm{NaOH}$ until yellow with phenol red; $\mathrm{N}-\mathrm{NaOH}$ was then used to finish neutralization. The glucose in $1 \mathrm{ml}$. of this extract was then estimated by the anthrone method of Trevelyan \& Harrison (1952). In both methods a control culture containing no maltose was subjected to the same procedure.

$M$ precipitin tests were carried out by the method of Swift, Wilson \& Lancefield (1943), on crude extracts prepared from $50 \mathrm{ml}$. broth cultures, and purified $\mathbf{M}$ extracts prepared from the crude extracts. Absorbed type-specific anti-M serum for type 19 was supplied by the Streptococcus Reference Laboratory. Anti-M sera against the variants of IRP 118 were prepared by injection of killed suspensions into rabbits and absorbed with heavy suspensions in the usual way.

Regeneration of $M$ antigen in vitro. This was studied by the method of Fox \& Krampitz (1956), and casein polypeptide was prepared by their method.

Virulence tests. Six mice/dilution were injected intraperitoneally with $1 \mathrm{ml}$. broth dilutions $\left(10^{-2}\right.$ to $\left.10^{-7}\right)$ of $2 \cdot 5 \mathrm{hr}$ cultures. The LD 50 was calculated after 
7 days by the method of Reed \& Muench (1938). Rat virulence was measured in the same way, using an intraperitoneal dose of $2 \mathrm{ml}$.

Resistance to phagocytosis was studied by three methods. (1) Direct and indirect bactericidal tests were carried out by the method of Lancefield $(1957,1958)$ with fresh heparinized human blood from donors whose sera did not contain the typespecific anti-M antibodies for types 19 or 12 . Overnight broth cultures were diluted in broth to provide a series of inocula in the range of 10-100 streptococcal chains, determined by viable counts in blood agar. Each bottle contained $0 \cdot 1 \mathrm{ml}$. culture dilution and $0.3 \mathrm{ml}$. blood. Duplicate cultures were prepared for each dilution, one being stationary and the other continuously rotated during incubation. After $4 \mathrm{hr}$ and again after $24 \mathrm{hr} 0.1 \mathrm{ml}$. of each mixture was seeded into blood agar pour plates for viable counts. In the indirect tests, $0.05 \mathrm{ml}$. of dilution of rabbit homologous anti-M serum was added to the mixtures. (2) Surface phagocytosis tests were carried out using mixtures of streptococci and human leucocytes spread on autoclavable Kleenex squares $(1 \times 2 \mathrm{~cm}$.). The leucocytes were collected from $30 \mathrm{ml}$. fresh heparinized human blood by the method of Baron \& Roberts (1963) modified by Dr Omar Ahmed (personal communication) as follows. Four vol. blood was diluted with 1 vol. $6 \%$ dextran in Hartman's solution and the tube stood at an angle of $45^{\circ}$ for $45 \mathrm{~min}$. The whole plasma layer was then centrifuged at $2000 \mathrm{rev} . / \mathrm{min}$. for $5 \mathrm{~min}$. and the supernatant discarded. The pellet of cells was shaken hard for $15 \mathrm{sec}$. in $1 \cdot 8 \mathrm{ml}$. distilled water and $0.6 \mathrm{ml}$. quadruple-strength Hartman's solution was quickly added and the suspension reshaken and finally centrifuged at $600-800 \mathrm{rev} / \mathrm{min}$. for about $4 \mathrm{~min}$. A leucocyte layer was obtained which when finally suspended in about $0.07 \mathrm{ml}$. Hartman's solution gave a cell count of about $3 \times 10^{6} / \mathrm{ml}$. An overnight culture of the test organism was diluted 1/10 in fresh broth, and gave a count of about $5 \times 10^{6}$ streptococcal chains $/ \mathrm{ml}$. About $0.07 \mathrm{ml}$. was mixed with the leucocytes and spread over three Kleenex squares previously moistened with gelatin + Locke solution, and mounted on a glass slide in a Petri dish lined with moist filter paper. This was then sealed and incubated at $37^{\circ}$. After incubation the squares were transferred to a bottle containing $2 \mathrm{ml}$. gelatin + Locke solution and shaken vigorously for about 30-45 sec. The suspension obtained was centrifuged for $1 \mathrm{~min}$. at $800 \mathrm{rev} . / \mathrm{min}$. The deposit containing leucocytes, phagocytosed streptococci and some free streptococci was suspended in $0.5 \mathrm{ml}$. physiological saline $+3 \%$ gelatin, and smears of the suspension were prepared and stained with methylene blue. A thousand leucocytes were counted to determine how many contained streptococci. (3) Phagocytosis in mouse peritoneum was studied by the method of Foley, Smith \& Wood (1959).

\section{EXPERIMENTAL}

\section{Isolation of starch-positive and starch-negative variants}

Variant streptococci which form starch from low concentrations of maltose $(\mathbf{0} \cdot \mathbf{1}-\mathbf{0} \cdot \mathbf{4} \%$ ) are present in primary cultures of many group $\mathbf{A}$ strains isolated from acute infections, and sometimes all the colonies on maltose screening medium may show some degree of blue staining with iodine. Both resting populations (Crowley, 1955) and lag phase organisms of such strains show amylomaltase activity. Certain strains which appeared to be starch-negative on many occasions even in the presence of very high maltose concentration $(>1.0 \%$ ) occasionally showed amylomaltase 
activity in the neighbourhood of plate contaminants (author's unpublished observations). An attempt was made to isolate pure cultures of starch-positive and starch-negative variants in order to study their properties separately. The strain IRP 118, type 19, was used because it was a very good starch producer from low maltose concentrations in many different kinds of culture medium. When the freeze-dried culture was first tested on $0.4 \%$ maltose agar, all the colonies of $10^{-3}$ to $10^{-5}$ dilutions contained some starch (see Pl. 1, fig. 1).

Using a series of replica platings, strongly starch-positive and weakly starchpositive variants were identified on maltose agar and propagated by indirect selection from either blood agar or glucose agar. Pure cultures of the variants were not obtained, though the differences in starch production between weakly and strongly starch-positive strains began to be more marked especially in overnight cultures. Colonies of streptococci arise from chains of various length, usually four to thirty cocci and occasionally from pairs, so broth cultures were subjected to ultrasonic treatment for $10 \mathrm{~min}$. or longer to break the chains. It was possible that some single cocci might survive to give rise to single-cell cultures. The procedure was repeated six times during another series of replica platings, and eventually produced a heterogeneous population from which the two variants used in this study were finally selected (Pl. 1, fig. 2, 3).

Whether the variant 7s3 designated 'starch-positive' was derived from a single streptococcus must always be uncertain, but the evidence that it was strongly starch-positive is shown in Tables 1 and 2. The variant $191 b$ designated 'starchnegative' was only so-called, for Tables 1 and 2 show that it produced small amounts of starch. In the first test to measure starch production (Table 1) single colonies. were seeded into maltose broth, and the starchy streptococci counted after 8,18 and $48 \mathrm{hr}$. Only all-blue cocci were counted, for in cultures of the starch-positive variant many cocci contained small spots or traces of starch, which were difficult. and tiring to count.

Table 1. Starch-containing streptococci in maltose broth cultures of variants of organism Group $A$ strain, IRP 118, type 19

\begin{tabular}{|c|c|c|c|}
\hline Hours at $37^{\circ}$ & 8 & 18 & 48 \\
\hline & \multicolumn{3}{|c|}{ Streptococci starch-positive* $(\%)$} \\
\hline Strains & \ulcorner & & \\
\hline IRP 118 before selection & 18 & 44 & \\
\hline Variant 7s3 starch-positive & 20 & 65 & \\
\hline Variant $191 b$ starch-negative & $\mathbf{3}$ & 6 & \\
\hline
\end{tabular}

* Starch-positive = chain containing two or more blue cocci in smears, stained by $1 \%$ Lugol's iodine, of deposit of $1 \%$ maltose broth cultures.

When after $18 \mathrm{hr}$ the culture deposits were suspended in fresh maltose broth and reincubated, the starchy cocci in cultures of the starch-positive strain continued to increase until more than $90 \%$ of the chains contained wholly starchy cells. In cultures of the starch-negative variant on the other hand, the numbers of starchy cocci decreased and disappeared, apparently diluted out. The difference between the two strains was confirmed by the results of quantitative assays of the amount of starch produced in maltose cultures. 
Table 2 shows the data for starch production by the parent strain before selection, and by the variants tested by method I. There was never any gross difference between the extinctions of suspensions of the three strains, nor of the growth in overnight cultures. The starch-negative variant always showed slightly more growth. Because the growth of the variants was comparable, no attempt was made to relate starch production to growth when using method 2. Extracts of the starch-positive variant contained 140-160 $\mu \mathrm{g}$. glucose/ml. extract, whereas comparable extracts of the starch-negative variant contained only $20-40 \mu \mathrm{g}$. glucose $/ \mathrm{ml}$. extract.

Table 2. The quantity of starch produced in maltose cultures of variants of group $A$ strain, type 19

\begin{tabular}{|c|c|c|}
\hline Strains & $\begin{array}{l}\text { Extinction } \\
(650 \mu)\end{array}$ & $\begin{array}{c}\text { Starch* } \\
(\%)\end{array}$ \\
\hline IRP 118 parent strain & $\begin{array}{l}(a) \dagger 45 \cdot 7 \\
\text { (b) } 46 \cdot 0\end{array}$ & $\begin{array}{l}1.5 \\
1.27\end{array}$ \\
\hline 7s3 starch-positive & $\begin{array}{l}\text { (a) } 47 \cdot 7 \\
\text { (b) } 54 \cdot 4\end{array}$ & $\begin{array}{l}>2 \cdot 0 \\
>2 \cdot 0\end{array}$ \\
\hline $191 b$ starch-negative & $\begin{array}{l}54 \cdot 4 \\
53 \cdot 1\end{array}$ & $\begin{array}{l}0 \cdot 39 \\
0 \cdot 34\end{array}$ \\
\hline
\end{tabular}

* \% starch $=$ mg. glucose in perchloric acid extract of deposit of $10 \mathrm{ml}$. streptococcal cell suspension $\times 0.90 /$ extinction of $10 \mathrm{ml}$. streptococcal suspension.

$\uparrow a$ and $b=$ duplicate cultures.

On blood agar both variants were almost indistinguishable from each other and from the parent strain. In this respect different mammalian blood, either horse, rabbit, sheep or human, made no significant difference. On maltose blood agar the colonies of the starch-negative variant appeared translucent in comparison to the opaque starchy colonies. Starch was not formed on maltose +horse blood agar. In broth cultures without added carbohydrate there was no significant difference in rate of growth.

The starch-positive variant formed starch from very low maltose concentrations, $0 \cdot 1-0 \cdot 2 \%$, and starch production was very little affected by changes in culture media, addition of blood or serum (excepting horse) or accessory growth factors such as purines to the least complex media. An occasional batch of pooled human serum caused a temporary suppression of starch production for as long as $48 \mathrm{hr}$. Crowley (1959) described an inhibitory effect by high serum concentration on starch production by certain group A strains, but increased production by other group A strains, usually amylase producers. The presence of quite small amounts of glucose in the medium, $0 \cdot 3-0 \cdot 4 \%$, caused suppression of amylomaltase activity, and on glucose + maltose agar the colonies were smaller than when either carbohydrate was used alone. The mechanism of the inhibition of streptococcus amylomaltase by glucose is not clear. Numerous compounds are not utilized in the presence of glucose, which prevents the formation of a great many enzymes (Pardee, 1961) though, to be inhibitory, glucose must be metabolized. Glucose may be used in preference to another carbohydrate, the 'diauxie' of Monod (1947). Cohen \& Monod (1957), however, suggested that starch-forming bacteria were unable to 
utilize glucose through lack of a glucose permease and, though impermeable to glucose, were permeable to maltose through a maltose permease.

The so-called starch-negative variant in contrast showed an increased growth on glucose + maltose agar. It did not usually produce any starch even with very high maltose concentration $(>\mathbf{1 . 0} \%$ ) in a great variety of cultural conditions, using differently constituted broths and nutrient agar bases. Starch was sometimes formed, however, in certain circumstances, in the neighbourhood of plate contaminants, for example Pl. 1, fig. 4. These belonged to a number of different bacterial species only occasionally identified because they were often killed by iodine. The effect was not related to maltose concentration, and the finding suggested that amylomaltase was formed in conditions of starvation of some compound utilized by competing bacteria. This suggestion was supported by the finding that the variants ceased to form amylomaltase when growing in fresh culture medium with maltose but without the contaminants. Intermittently the starch-negative variant formed amylomaltase in culture plates prepared with certain batches of nutrient agar, also suggesting that the inducing factor might be a lack of a particular nutrient.

\section{$M$ antigen production}

The initiation of infection by group $\mathbf{A}$ streptococci in the human or mouse host depends on the type-specific $M$ antigen (Lancefield, 1940; Rothbard, 1948; Morris \& Seastone, 1955; Lancefield, 1954, 1957, 1958, 1959; Wiley \& Wilson, 1956; Foley et al. 1959). The $M$ antigen is anti-phagocytic and differences in mouse virulence are primarily related to its quantity and stability. It enables strains to resist the bactericidal power of fresh human blood, and to grow in blood from very small inocula. Both the parent strain and the two kinds of variant seemed to have plenty of $\mathbf{M}$ antigen in precipitin tests, the results of which are shown in Table 3.

Table 3. $M$ precipitin tests on starch-positive and starch-negative variants of group $A$ streptococcus, strain IRP 118

\begin{tabular}{|c|c|c|c|c|c|c|c|}
\hline \multirow[b]{2}{*}{ Strains } & \multicolumn{6}{|c|}{$\begin{array}{c}\text { Cell extracts + absorbed type } 19 \text { anti-M serum. } \\
\text { Antigen dilutions }\end{array}$} & \multirow[b]{2}{*}{$1 / 64$} \\
\hline & $\mathbf{0}$ & $1 / 2$ & $1 / 4$ & $1 / 8$ & $1 / 16$ & 1/32 & \\
\hline \multicolumn{8}{|c|}{ Starch-positive } \\
\hline $\begin{array}{c}\text { 7s 8, before mouse-passage } \\
\text { 9th mouse-passage } \\
\text { 16th mouse-passage } \\
\text { 20th mouse-passage* }\end{array}$ & $\begin{array}{l}+++ \\
+++ \\
+++ \\
+++\end{array}$ & $\begin{array}{l}++ \\
++ \\
++ \\
++\end{array}$ & $\begin{array}{l}+ \\
+ \\
+ \\
+\end{array}$ & $\begin{array}{l} \pm \\
\pm \\
\pm \\
+\end{array}$ & $\begin{array}{l}\mathbf{0} \\
0 \\
0 \\
+\end{array}$ & $\begin{array}{l}\mathbf{0} \\
\mathbf{0} \\
\mathbf{0} \\
\mathbf{0}\end{array}$ & $\begin{array}{l}\mathbf{0} \\
\mathbf{0} \\
\mathbf{0} \\
\mathbf{0}\end{array}$ \\
\hline \multicolumn{8}{|c|}{ Starch-negative } \\
\hline $\begin{array}{c}191 b \text {, before mouse-passage } \\
\text { 8th mouse-passage } \\
\text { 23rd mouse-passage }\end{array}$ & $\begin{array}{l}+t+ \\
+++ \\
++t\end{array}$ & $\begin{array}{l}+t \\
+t \\
++\end{array}$ & $\begin{array}{l}++ \\
++ \\
+\end{array}$ & $\begin{array}{l}+ \\
+ \\
+\end{array}$ & $\begin{array}{l} \pm \\
\pm \\
\pm\end{array}$ & $\begin{array}{l} \pm \\
\mathbf{0} \\
\pm\end{array}$ & $\begin{array}{l}\mathbf{0} \\
\mathbf{0} \\
\mathbf{0}\end{array}$ \\
\hline
\end{tabular}

The $\mathbf{M}$ antigen is destroyed by trypsin. Studying the synthesis of $\mathbf{M}$ antigen by a type 14 strain, Fox \& Krampitz (1956) found that, after its destruction by trypsin, it reappeared on the streptococci after as little as $1.5 \mathrm{hr}$ in favourable cultural 
conditions. They also found that, for the maximum synthesis of $\mathbf{M}$ antigen, glucose, together with certain amino acids and polypeptides, was an essential growth requirement. It seemed possible that, because of their differences in carbohydrate metabolism, the two variants might produce $\mathbf{M}$ antigen at different rates. If, for example, the starch-positive variant failed to metabolize glucose it might be sluggish in manufacture of $M$ antigen at an early phase of growth, and this might affect its survival in the presence of phagocytes. In blood broth without additional carbohydrate both variants, after stripping of $\mathbf{M}$ antigen by trypsin, produced it again after 1.5-2 hr. The addition either of glucose or of maltose to the medium had no effect on the $M$ regeneration time of the starch-positive variant, but shortened that of the starch-negative variant to $1-1.5 \mathrm{hr}$. Both variants also produced $\mathbf{M}$ antigen in the $2.5 \mathrm{hr}$ broth cultures used for virulence tests. There was obviously no gross difference between the variants regarding $\mathbf{M}$ antigen synthesis in vitro, but these findings, together with those in Table 3, suggested that the starch-negative variant produced rather more $\mathrm{M}$ antigen than the starch-positive strain.

\section{Capsule production}

The second, though lesser, factor in the antiphagocytic complex of group A streptococci is the hyaluronic acid capsule (Rothbard, 1948; Foley et al. 1959; Hirsch \& Church, 1960). The variants both formed mucoid colonies; both produced well defined but not outstandingly large capsules in $2.5 \mathrm{hr}$ broth cultures. These were also present after $4 \mathrm{hr}$ when there was no difference between the variants. After $6 \mathrm{hr} 94 \%$ of the starch-negative variants were still capsulated, compared with $35 \%$ of the starch-positive variants. After $16 \mathrm{hr}$ capsular material had gone from both. Whilst here again there was no gross difference between the strains regarding capsular synthesis, the capsules of the starch-positive variant were less stable. Foley \& Wood (1959) showed that in phagocytic tests done in roller tubes streptococci with large capsules, even though they had no $M$ protein, were resistant to phagocytosis. It remained to be seen whether the slight differences between the variants affected mouse virulence.

\section{Mouse virulence}

The variants had been cultured for months without mouse passage, and at first both were less virulent than the parent strain, the LD 50 of which was in the range $1 \times 10^{2}$ to $1 \times 10^{4}$. Serial mouse passage quickly restored the virulence of the starchnegative variant, which had an LD50 of 10 to 100 chains after a few passages. The mouse-history of the starch-positive variant is illustrated in Fig. 1 and shows that after 9 passages it still had a low virulence but, after the 10th passage, the LD 50 was 1 to 5 . The streptococci recovered from the 10 th mouse $(10 \mathrm{~B})$ were, however, starch-negative. The 9th mouse strain still starch-positive was then reinjected into another mouse (10 $\mathrm{A}$ ), and then the organisms recovered were still starch-positive but again of low virulence. Figure 1 shows that the virulence of all the starchpositive mouse lines was of the same low order, but when starch-negative streptococci were again recovered from certain mice (29 and 37) there was a sudden enhancement of virulence.

Mouse-selected starch-negative strains. Like those selected from culture plates, 
the mouse-selected starch-negative variants formed small amounts of starch in certain circumstances. The inducing factors were the same, namely plate contaminants and particular batches of nutrient agar base. An apparently total change from starch-positive to negative happened in three of seventy mice. An obviously mixed culture was recovered from one mouse (12 AG not shown) which had an intermediate virulence but was not further studied. If the original starch-positive variant $7 \mathrm{~s} 3$ was a heterogeneous culture, it was surprising that the change-over did not occur more often, and it seems more likely that the virulent variants arose by mutation in the mouse.

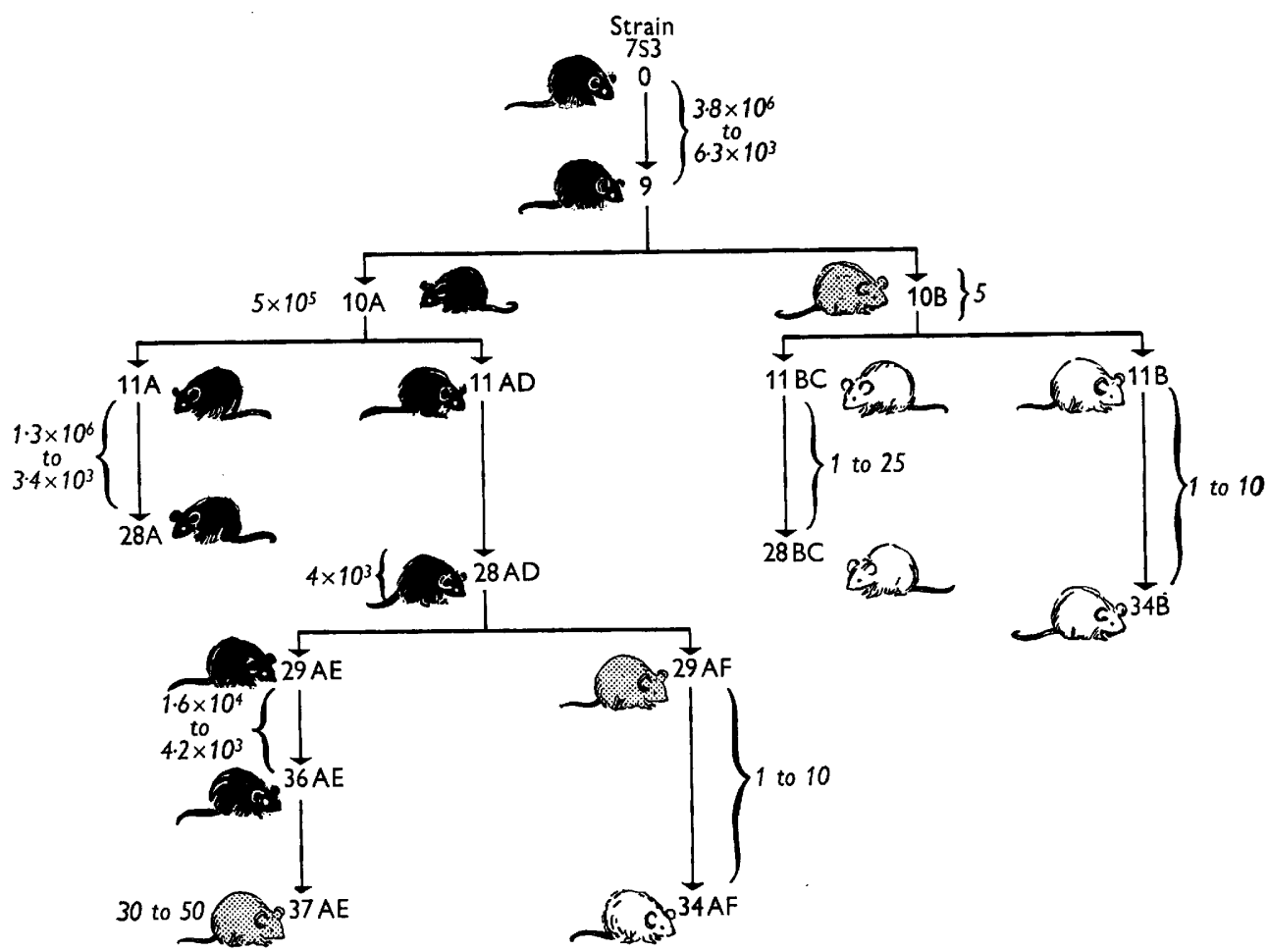

Fig. 1. The recovery of starch-negative variants of high mouse virulence from mice injected with starch-positive variants of low mouse virulence.

Mice

(c) starch-positive organisms injected and recovered.

(.) starch-positive organisms injected but starch-negative organisms recovered.

starch-negative organisms injected and recovered.

Figures in italics-lowest and highest LD50 recorded on strain during course of mouse passage. Figures in ordinary type, number of mouse passages.

Phagocytosis in mouse peritoneum. In mouse peritoneal exudates which were examined at hourly intervals after injection the starch-negative variant was clearly less susceptible to phagocytosis by mouse leucocytes than the starch-positive variant. These results, which are shown in Table 4, were consistent with the differ- 
ences in mouse virulence. By $\mathbf{M}$ precipitin tests, however, both strains appeared to have plenty of $\mathbf{M}$ antigen.

Rat virulence. Foley et al. (1959) found that the virulence of group A strains in rats, as in mice, was closely related to their ability to resist surface phagocytosis, and this in turn was related to the amount of $\mathbf{M}$ antigen produced by the strains. They also found that two strains with a mouse LD50 of 1 were considerably less virulent for rats $\left(1 \times 10^{3}\right.$, and $\left.2 \cdot 1 \times 10^{7}\right)$. The rat $\mathbf{L D} 50$ of the starch-negative variant was $7 \cdot 6 \times 10^{5}$, though the mouse LD50 was 1 to 10 chains, which demonstrated that an amount of $\mathbf{M}$ antigen which was abundant for resisting phagocytosis in mice was inadequate for the same purpose in rats. The LD50 for rats of the starch-positive variant was $>1 \times 10^{7}$. The rat is of course highly resistant to bacterial infections to which other laboratory animals are susceptible and some other factor may be involved in rat virulence of group A strains.

Table 4. Phagocytosis of starch-positive and starch-negative variants of group $A$ streptococcus strain in mouse peritoneum

\begin{tabular}{|c|c|c|c|c|c|}
\hline \multirow[b]{2}{*}{ Strains } & \multirow[b]{2}{*}{ Mouse peritoneal exudates } & \multicolumn{4}{|c|}{ Time after injection $(\mathrm{hr})$} \\
\hline & & 1 & 2 & $\mathbf{3}$ & 4 \\
\hline \multicolumn{6}{|c|}{ Starch-positive } \\
\hline $\begin{array}{l}\text { 7s3A/20 } \\
\text { LD 50, 3.4 } \times 10^{8}\end{array}$ & $\begin{array}{l}\text { \% phagocytes containing streptococci } \\
\text { Extracellular streptococci }\end{array}$ & $\begin{array}{r}>1 \\
\text { Few }\end{array}$ & $\begin{array}{r}3 \\
\text { Few }\end{array}$ & $\begin{array}{r}8 \\
\text { Few }\end{array}$ & $\begin{array}{c}14 \\
\text { Few }\end{array}$ \\
\hline \multicolumn{6}{|c|}{ Starch-negative } \\
\hline $\begin{array}{l}7 \mathrm{sBc} / 20 \\
\mathrm{LD50}, 1\end{array}$ & $\begin{array}{l}\text { \% phagocytes containing streptococci } \\
\text { Extracellular streptococci }\end{array}$ & $\begin{array}{r}<1 \\
+\end{array}$ & $\begin{array}{c}<1 \\
+\end{array}$ & $\begin{array}{c}<1 \\
\pm\end{array}$ & $\begin{array}{c}8 \\
+++\end{array}$ \\
\hline
\end{tabular}

The starch-negative variant was the mouse-selected strain recovered from a mouse injected witha starch-positive strain. The figure after the stroke $=$ no. of serial mouse passages of variant.

\section{Resistance to phagocytosis by human leucocytes}

Man is the natural host of the group A streptococcus, and he may be more susceptible to infection than the mouse, for freshly isolated strains which seem to have plenty of $M$ antigen frequently have a very low mouse virulence. Strains with large amounts of $\mathbf{M}$ antigen are resistant to phagocytosis in fresh human blood when the cultures are rotated so that the streptococci are in constant touch with leucocytes (Lancefield, 1957, 1958, 1959). When anti-M serum is added the streptococci become susceptible to phagocytosis (indirect bactericidal test). Lancefield (1959) devised a rough quantitative measure of $M$ antigen of strains by comparing the amount of growth in rotated and stationary cultures, for heavy growth from rotated cultures showed good M antigen production. She also found that when strains had large amounts of $M$ antigen, only neat anti-M serum neutralized the anti-phagocytic effect, whereas diluted anti-M serum was adequate for strains with lesser amounts.

\section{Growth in fresh human blood}

Direct bactericidal tests were carried out frequently on the variants before and during mouse passage, and also on the mouse-selected starch-negative variants of high virulence. In rotated blood cultures, growth equal to more than twice the original inoculum, obtained after $4 \mathrm{hr}$, was considered to be good evidence of anti- 
phagocytic power. Heavy growth after $24 \mathrm{hr}$ was considered very good. Neither variant grew out well on every occasion, as shown in Table 5, but both showed good growth in the majority of the tests, and very good growth in about a third. Inconsistencies attributable to technical error or change of blood donor were evenly distributed between the variants. These results, which suggested that there was no significant difference between them with respect to anti-phagocytic power against human leucocytes, were poorly correlated with mouse virulence.

Table 5. Growth of starch-positive and starch-negative variants of group $A$ streptococcus, strain IRP 118, in fresh human blood (direct bactericidal tests)

$\begin{array}{lcc}\begin{array}{c}\text { No. streptococci recovered } \\ \text { from rotated cultures }\end{array} & \overbrace{\begin{array}{c}\text { Starch- } \\ \text { positive } \\ (28 \text { tests })\end{array}}^{\text {Variants }} & \begin{array}{c}\text { Starch- } \\ \text { negative } \\ (23 \text { tests) }\end{array} \\ \begin{array}{l}\text { More than twice the original inoculum } \\ \text { Equal to or less than original inoculum }\end{array} & 9(9)^{*} & 17(8)\end{array}$

* No. of tests showing growth after $4 \mathrm{hr}$. In parentheses no. of tests showing heavy growth after $24 \mathrm{hr}$.

Heavy growth was always recovered from stationary cultures of both variants.

Indirect bactericidal tests were carried out using a homologous anti-M rabbit serum, undiluted and diluted $1 / 5$ in the blood cultures. Very good growth was obtained from both variants using normal rabbit serum, and $1 / 5$ anti-M serum in the cultures. Though the variants grew in the presence of undiluted anti-M serum the bacterial counts of both were reduced in rotated cultures. It was still not possible to demonstrate any significant difference between the $\mathbf{M}$ content of the two strains with this anti-M serum; this is being further studied using other anti-M sera.

\section{Surface phagocytosis tests}

In the conditions of the human blood bactericidal test as devised by Lancefield, the leucocytes outnumber the streptococci by about a million to one, which would seem to be a stringent trial of the anti-phagocytic power of the organisms. Foley et al. (1959), however, found that differences in susceptibility of group A strains to phagocytosis in vitro by mouse and rat leucocytes were demonstrable on filter paper when not apparent in tests performed on glass slides or in roller tubes. In surface tests the leucocytes and organisms encounter each other on pieces of freshly excised tissue or on moistened filter paper, which provide a rough surface on which the leucocytes can trap the organisms more easily than in a liquid medium Wood, Smith \& Watson (1946). Table 6 shows the results of surface type tests done on the variants using human leucocytes from peripheral blood. The conditions here were weighted a little in favour of the organisms because there were rather more streptococci than leucocytes. The amount of culture medium was negligible so there was no question of growth, as in the bactericidal or virulence tests. A non-virulent strain, type 6 glossy, which has no $M$ antigen and does not survive in direct bactericidal tests with human blood was used for comparison, and proved to be relatively the most susceptible to surface phagocytosis. There was no significant difference between 
the anti-phagocytic power of the starch-positive and starch-negative variants in these conditions in spite of their differing mouse virulence. Capsular material had disappeared from the overnight cultures used in these tests, so that the $M$ antigen was the only known anti-phagocytic factor concerned.

Table 6. Anti-phagocytic power of starch-positive and starch-negative variants against human leucocytes on paper (surface phagocytosis) compared with a virulent strain type 6 , glossy

\begin{tabular}{|c|c|c|c|}
\hline Variants & $\begin{array}{c}\text { Time at } \\
\mathbf{3 7}{ }^{\circ} \\
(\mathbf{h r})\end{array}$ & $\begin{array}{l}\text { Leucocytes } \\
\text { containing } \\
\text { streptococei } \\
\text { (\% total) }\end{array}$ & $\begin{array}{l}\text { LD 50 } \\
\text { (mice) }\end{array}$ \\
\hline \multicolumn{4}{|c|}{ Starch-positive } \\
\hline $7 \mathrm{~s} 3 \mathrm{~A} / 25$ & $\begin{array}{l}2 \\
4\end{array}$ & $\begin{array}{l}<1.0 \\
<1.0\end{array}$ & $1.8 \times 10^{8}$ \\
\hline $7 \mathrm{s3A} / 26$ & 4 & $<1.0$ & \\
\hline \multicolumn{4}{|c|}{ Starch-negative } \\
\hline $7 \mathrm{~s} 3 \mathrm{c} / 25$ & $\begin{array}{l}2 \\
4\end{array}$ & $\begin{array}{r}<\mathbf{1} \cdot \mathbf{0} \\
\mathbf{3} \cdot 0\end{array}$ & 5 \\
\hline $7 \mathrm{~s} 3 \mathrm{c} / 26$ & 4 & $2 \cdot 2$ & \\
\hline Type 6 glossy & $\begin{array}{l}2 \\
4\end{array}$ & $\begin{array}{l}4 \cdot 8 \\
8 \cdot 2\end{array}$ & $>1 \times 10^{8}$ \\
\hline
\end{tabular}

Table 7. Summary of anti-phagocytic properties of starch-positive and starch-negative variants in different conditions

Phagocytic test

Human whole blood rotated cultures Human leucocytes on paper Mouse peritoneum Rat peritoneum

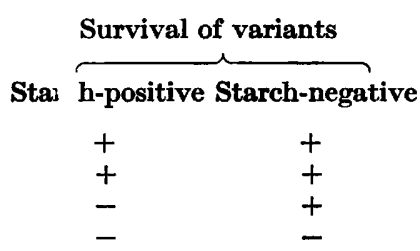

The conflicting results of the in vitro and in vivo phagocytic tests as a rough quantitative measurement of differences in $\mathbf{M}$ antigen content of the variants are summarized in Table 7. It seemed possible that these findings might be explicable if viewed in relation to the growth requirements of the starch-positive variant in addition to its anti-phagocytic powers.

Bacon, Burrows \& Yates (1951) found that biochemical mutants of Salmonella typhi were avirulent for mice. In particular the virulence of mutants which could not synthesize purines was of a very low order, and mouse peritoneal fluid though rich in other growth factors was low in purines. There is no evidence that the growth in vitro of the starch-positive variants is particularly improved by purines, but there is no doubt that compared with starch-negative variants they are dependent on accessory growth factors present in highly complex culture media containing blood or serum. Woolley (1941) found that a mixture of peptides which he called strepogenin was necessary for the growth of certain group A strains and related to protein synthesis. Fox \& Krampitz (1956) showed that casein polypeptides greatly increased the rate of $M$ antigen synthesis. The possibility that mouse or rat peritoneal 
fluid was a poor culture medium for the starch-positive variants was then investigated, with particular reference to peptide deficiency. The mouse virulence of the starch-positive variant was retested by adding casein polypeptide $(1 \%, \mathrm{w} / \mathrm{v})$ to each of the test dilutions. The results shown in Table 8 strongly supported the idea that the low mouse virulence of the variant was due to its need for an accessory growth factor in the environment of mouse peritoneum, rather than lack of anti-phagocytic power.

The effect of other peptide preparations on mouse virulence is being further studied. Table 8 shows that an addition of a $5 \%$ human red cell suspension to the test dilutions had no comparable effect on the LD 50, whereas an addition of $20 \%$ human plasma had an effect of the same order as the casein polypeptide.

Table 8. The effect of casein polypeptide on the mouse-virulence of the starch-positive variant strain $7_{s 3 / A 29}$

\begin{tabular}{ll}
\multicolumn{1}{c}{ Strain diluted in } & \multicolumn{1}{c}{ LD 50 } \\
for mice
\end{tabular}

* The casein polypeptide solution was non-toxic for mice when injected intraperitoneally.

\section{Production of anti- $M$ sera}

Really good anti-M sera against either of the variants have not so far been produced, though the most acceptable was prepared with the starch-negative variant. The possible significance of his in relation to the starch-positive variant is being further studied. Cross-absorytion experiments did not suggest that there was any antigenic difference between the strains. $M$ antigen extracts and concentrated M antigen extracts were analysed by immuno-electrophoresis by Dr Armine T. Wilson (Wilmington, Delaware personal communication), who could not demonstrate any immunological difference between the $\mathbf{M}$ antigens of the two variants.

\section{Variants from another group $A$ strain}

A starch-positive variant was isolated by the same methods from another group $\mathbf{A}$ strain, OP, PS, type 12, and compared with a starch-negative variant from the same parent. This strain was chosen at random for the second study because it was a good starch producer, very like IRP 118, but a member of another serotype. Both variants grew vigorously in direct bactericidal tests with human blood and resisted phagocytosis in surface tests with human leucocytes. The starch-positive variant $(30 \mathrm{~B})$ was non-virulent for mice $\left(\right.$ LD $\left.50>1 \times 10^{6}\right)$ whereas the starch-negative variant (29) was relatively virulent (LD 50, 100-300). This finding supported the idea that the properties described apply to starch-positive variants in general and not only to one from a particular parent strain. 


\section{DISCUSSION}

When working on the pathogenicity of group A streptococci it is customary to mouse-passage strains frequently to keep up their virulence. The present work has demonstrated the futility of this procedure in relation to the particular property being studied for regular amylomaltase production seems to be incompatible with high mouse virulence, when the test dilutions are made in the usual way. Many freshly isolated group A strains which seem to have plenty of $M$ antigen in precipitin tests and are causing infections, may not be mouse-virulent. This puzzling discrepancy may be accounted for by the presence of starch-positive variants in the primary cultures, starch-production from maltose being a marker for streptococci which in vitro very quickly become starved of an accessory growth factor. It remains to be seen whether this finding is relevant to human disease.

I wish to thank the Medical Research Council for the grant which supported this work and Josephine Prescott and Clare Notley for their excellent technical help. I also wish to thank Dr M. T. Parker, (Streptococcus Reference Laboratory, Colindale), for supplies of anti-M sera, Dr Armine T. Wilson, (Alfred I. du Pont Institute of the Nemours Foundation, Wilmington), for the immuno-electrophoretic patterns of the M extracts, Dr Omar Ahmed, (Chemical Pathology Department, Royal Free Hospital), for valuable help and advice on collecting human leucocytes and Miss Marjorie Smith, medical artist, for drawing Fig. 1.

\section{REFERENCES}

Bacon, G. A., Burrows, T. W. \& Yates, M. (1951). The effects of biochemical mutation on the virulence of Bacterium typhosum: the loss of virulence of certain mutants. Brit. J. exp. Path. 32, 85.

Baron, D. N. \& Roberts, P. M. (1963). The sodium, potassium and water content of isolated normal human leukocytes. J. Physiol. 165, 219.

Baum, H. \& Crowley, N. (1960). Starch-like polysaccharide of Streptococcus pyogenes. Nature, Lond. 187, 413.

Cohen, G. N. \& Monon, J. (1957). Bacterial permeases. Bact. Rev. 21, 169.

Crowley, N. \& Jevons, M. P. (1955). The formation of a starch-like polysaccharide from maltose by strains of Streptococcus pyogenes. J. gen. Microbiol. 13, 226.

Crowley, N. (1955) The action of streptococcal amylase in relation to the synthesis of an amylosacchande by amylolytic strains of Streptococcus pyogenes. J. gen. Microbiol. $13,218$.

Crowley, N. (1959). The association of starch-accumulating strains of group A streptococci with acute nephritis and acute rheumatic fever. J. Hyg., Camb. 57, 235.

Foley, M. J., Smith, M. R. \& Wood, W. B. (1959). Studies on the pathogenicity of group A streptococci. I. Its relation to surface phagocytosis. J. exp. Med. 110, 603.

Foley, M. J. \& Woon, W. B. (1959). Studies on the pathogenicity of group A streptococci. II. The anti-phagocytic effects of the $M$ protein and the capsular gel. J. exp. Med. $110,617$.

Fox, E. N. \& Krampitz, L. O. (1956). Studies on the biosynthesis of the M protein of group A haemolytic streptococei. J. Bact. 71, 454.

Hirsch, J. G. \& Church, A. B. (1960). Studies of phagocytosis of group A streptococci by polymorphonuclear leukocytes in vitro. J. exp. Med. 111, 309.

LANCEFIELD, R. C. (1940). Specific relationship of cell composition to biological activity of haemolytic streptococci. Harvey Lect. 36, 251. 
LANCEField, R. C. (1954). Cellular constituents of group A streptococci concerned in antigenicity and virulence. In Streptococcal Infections. Ed. by M. McCarty. New York: Columbia University Press.

LANCEFIELD, R. C. (1957). Differentiation of group A streptococci with a common $\mathbf{R}$ antigen into three serological types with special reference to the bactericidal test. J. exp. Med. 106, 525.

LANCEFIELD, R. C. (1958). Occurrence of $\mathrm{R}$ antigen specific for group A, Type 3 streptococci. J. exp. Med. 108, 329.

Lancefueld, R. C. (1959). Persistence of type-specific antibodies in man following infection with group A streptococci. J. exp. Med. 110, 271.

Lederberg, J. \& Lederberg, E. M. (1952). Replica plating and indirect selection of bacterial mutants. J. Bact. 63, 399.

Monod, J. (1947). The phenomenon of enzymatic adaptation and its bearings on problems of genetics and cellular differentiation. Growth, 11, 223.

Monod, J. \& Torriani, A. M. (1950). De l'amylo-maltase d'Escherichia coli. Ann. Inst. Pasteur, 78, 65.

Morris, M. \& Seastone, C. V. (1955). The relationship of M protein and resistance to phagocytosis in the beta haemolytic streptococci. J. Bact. 69, 195.

Pardee, A. B. (1961). Response of enzyme synthesis and activity to environment. In Microbial Reaction to Environment. Symp. Soc. gen. Microbiol. 11, 19.

Pucher, G. W., LeVenworth, C. S. \& Vickery, M. B. (1948). Determination of starch in plant tissues. Analyt. Chem. 20.

Reed, L. J. \& Muench, H. (1938). A simple method of estimating $50 \%$ endpoints. Amer. J. Hyg. 27, 493.

Rothbard, S. (1948). Protective effect of hyaluronidase and type-specific anti-M serum on experimental group A streptococcus infections in mice. J. exp. Med. 88, 325.

SwifT, H. F., Wilson, A. T. \& Lancefield, R. C. (1943). Typing group A haemolytic streptococci by $M$ precipitin reactions in capillary pipettes. J. exp. Med. 78, 127.

Trevelyan, W. E. \& Harrison, J. S. (1952). Studies on yeast metabolism. Biochem. J. 50, 298.

Wiley, G. G. \& Wilson, A. T. (1956). The ability of group A streptococci killed by heat or mercury arc irradiation to resist ingestion by phagocytes. J. exp. Med. 103, 15.

Wood, W. B., Smith, M. R. \& Watson, B. (1946). Studies on the mechanism of recovery in pneumococcal pneumonia. IV. The mechanism of phagocytosis in the absence of antibody. J. exp. Med. 84, 387.

Woolley, D. W. (1941). A new growth factor required by certain hemolytic streptococci. J. exp. Med. 73, 487.

\section{EXPLANATION OF PLATE}

Fig. 1. Streptococcal culture before selection of variants; maltose agar, $24 \mathrm{hr}$ after exposure to iodine vapour.

Fig. 2. Heterogeneous culture of starch-positive and starch-negative colonies produced by subjecting broth culture of the strain to ultrasonic vibration.

Fig. 3. Starch-positive and starch-negative variants $7 \mathrm{~s} 3$ and $191 b$ selected from IRP 118 .

Fig. 4. Starch-negative strain on maltose agar showing starch production in the neighbourhood of plate contaminants. 

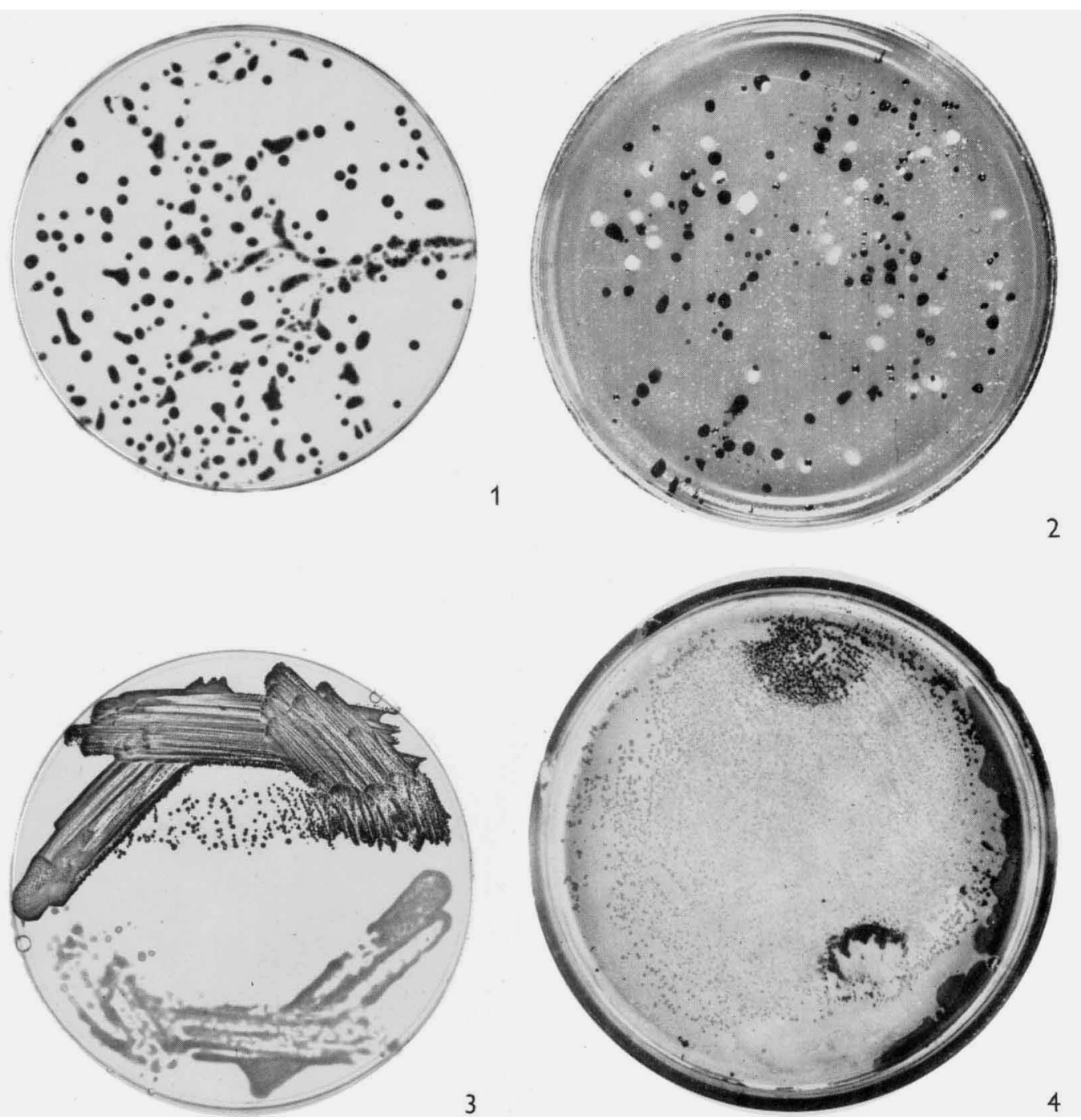